\title{
Pionerismo relativo y autoría compartida. Mito contra Historia del cine español
}

\author{
Agustín Rubio Alcover \\ Universitat Jaume I de Castellón \\ rubioa@uji.es
}

\begin{abstract}
Resumen
La moderna historiografía del cine español ha tendido a parcelarse en función de opciones metodológicas e ideológicas. Asimismo, las consignas antiempiristas y antipositivistas han tenido efectos perversos para un auténtico conocimiento del devenir de nuestra cinematografía, en particular por lo que respecta a su industria y al papel de los sujetos en la evolución de la misma. El presente trabajo aspira a terciar en este debate, y a aportar una propuesta de encuentro, razonada, crítica, constructiva y concreta. Para ello, se sirve de tres películas españolas clásicas -a saber: Goyescas (Benito Perojo, 1942), La calle sin sol (Rafael Gil, 1948) y Los peces rojos (José Antonio Nieves Conde, 1955)-, para aportar, respectivamente, datos en torno a la génesis de la primera; a la novedad técnica de la segunda; y a la autoría de la tercera. Con estos tres ejemplos, el autor señala cuál es la naturaleza de las lagunas historiográficas que en estos momentos son, a su juicio, más acuciantes; reordena las prioridades; argumenta las estrategias que considera más adecuadas para cubrir aquellos huecos; e ilustra el rendimiento que puede obtenerse de un uso equilibrado y no excluyente de las técnicas y las tecnologías tradicionales y contemporáneas, para un entendimiento más sistemático del objeto de estudio.
\end{abstract}

Palabras clave Cine español, Historia del Cine, pionerismo, autoría, tecnología, mitología

\section{Relative Pioneering and Shared Authorship. Myth versus History of the Spanish Cinema}

\begin{abstract}
The modern historiography of the Spanish movies has tended to divide into lots, in terms of methodological and ideological options. In like manner, anti-empiricist and anti-positivist slogans have had perverse effects for an authentic knowledge of the vicissitude of our cinematography, in particular for its industry and the paper of the subjects in the evolution of the same. The present work aspires to arbitrate this debate, and to contribute a proposal of encounter, reasoned, critical, constructive and concrete. Three Spanish classical films - namely: Goyescas (Benito Perojo, 1942), La calle sin sol (Rafael Gil, 1948) and Los peces rojos (José Antonio Nieves Conde, 1955) - are used to contribute, respectively, data about the genesis of the first; the second's technical new thing; and the authorship of the third one. With these three examples, the author indicates which is the nature of the historiographical lagoons that are, to his judgment, more urgent; reorganizes priorities; arguments the strategies that may be considered best-suited to cover those holes; and illustrates the performance that can be obtained of a well-balanced and not excluding use of the techniques and the traditional and contemporaries technologies, for a most systematic understanding of the object of study.
\end{abstract}

Key Words Spanish Cinema, Film History, pioneering, authorship, technology, mythology

\section{Referencia normalizada:}

Rubio Alcover, A. (2013) Pionerismo relativo y autoría compartida. Mito contra Historia del cine español. Historia y Comunicación Social. Vol. 18 Nº Especial Octubre. Págs. 307-316 
Sumario 1. Introducción. 2. Tres películas, tres síntomas. 2.1. Tapices y caprichos: Goyescas (Benito Perojo, 1942). 2.2. La virtud en el error: La calle sin sol (Rafael Gil, 1948). 2.3. Una imaginación desorbitada: Los peces rojos (José Antonio Nieves Conde, 1955). 3. Conclusiones.

\section{Introducción}

El presente texto pretende retrotraerse y concretar los presupuestos metodológicos en que se funda la moderna historiografía del cine español. Para ello, se abordarán a través de tres ejemplos nobles -Goyescas (Benito Perojo, 1942); La calle sin sol (Rafael Gil, 1948) y Los peces rojos (José Antonio Nieves Conde, 1955)- ciertos problemas comunes, para proponer soluciones prácticas y constructivas, así como deshacer equívocos que son fruto de ciertas consignas (antipositivistas, antiempiristas, antibiografistas...) tan perniciosas como extendidas.

\section{Tres películas, tres síntomas}

\subsection{Tapices y caprichos: goyescas (benito perojo, 1942)}

La reciente localización de un cuadernillo de veintitrés páginas modifica el relato acerca de la génesis y la autoría de Goyescas, uno de los films de Benito Perojo emblemáticos de la postguerra española. Hasta la fecha, según el estudio de referencia del cineasta madrileño que escribió Román Gubern, se creía que Perojo había rehecho a su antojo un argumento pergeñado casi dos décadas antes por el libretista habitual de Enrique Granados, Fernando Periquet de Zuaznabar, para una ópera concebida en 1911 y que se estrenó en sucesivas versiones hasta el año 1916. Gubern daba por seguro que Perojo se había llevado el esquema original a su terreno hasta el punto de dejarlo irreconocible:

"Imperio Argentina recuerda que la colaboración de Rogelio Periquet (hijo del autor) fue meramente simbólica y que el guión fue obra de Perojo y de su esposa, colaboradora habitual en sus guiones" (1994: 360).

El texto inédito antes aludido contradice esta interpretación. Con cuatro títulos propuestos ("Aventura Goyesca" o "Goyescas" o "En tiempo de Goya pasó..." o "La maja de Goya") en una portada fechada en 1941, el guión que contiene no está datado, si bien es a todas luces muy anterior. El nombre del autor original está tachado y corregido, dos veces (al comienzo del texto, en la quinta página, tras una hoja de instrucciones; y en la última): en lugar de Fernando Periquet de Zuaznabar -el segundo apellido resulta legible, a pesar del borrón-, una misma mano anónima imputa la responsabilidad a Fernando Rogelio, o Rogelio Fernando -porque en un caso añadía "Rogelio" antes de "Fernando", y en el otro después- Periquet Rufilanchas. Que el responsable de los cambios debió de ser la única persona directamente beneficiada parecía corroborarlo otro detalle: el creador primitivo había dispuesto 
que la película proyectada se iniciara con un "Retrato de Fernando Periquet, autor de la película". Pues bien, el corrector fue un paso más allá, y sobrescribió: "Comienza la película con la fotografía del autor".

Los interesados, Fernando y Rogelio Fernando (o Fernando Rogelio) Periquet, de Zuaznabar y Rufilanchas respectivamente, eran padre e hijo. El primero era el letrista habitual de Enrique Granados, había escrito el libreto de una ópera titulada Goyescas estrenada a mediados de los años diez, y falleció en 1940. Rogelio, por el contrario, era abogado. Aparte de este crédito cinematográfico, solo consta entre los méritos del hijo que hubiera estado implicado en una segunda producción: Audiencia pública, de Florián Rey (1946), basada en casos reales en los que resulta verosímil que hubiera puesto el saber acumulado en sus años de ejercicio profesional. La fecha de 1941 sirve para acotar el momento en que se debió de exhumar el texto y llegar a Perojo. Tanto el estilo de la edición como la prosa y la extensión, anacrónico todo ello con respecto a los usos estandarizados en el cine español de la tercera década del XX (verboso, sin más separación entre descripción de las imágenes y comentario por los títulos que paréntesis y cursivas), inducen a pensar que el guión había sido escrito en el segundo lustro de los años diez.

Todo indica, pues, que Periquet padre había desarrollado un guión cinematográfico a partir del esquema zarzuelero hecho para Granados, con la esperanza de dar el salto al cine; que debía de guardar similitud con aquél, pero no ser idéntico (pues transcurrieron varios años entre uno y otro); que el empeño se había quedado en agua de borrajas; y que, casi dos décadas después -a la muerte de su progenitor-, su hijo se adueñó de la idea del padre para relanzar un proyecto que, esta vez sí, había llegado a ver la luz, con las modificaciones que fuere.

La segunda sorpresa viene al cotejar este guión con el argumento del film de 1942. Subtitulado "Escenas españolas contemporáneas de Goya" y dividido (a diferencia de sus precedentes, en dos cuadros o tres actos) en cuatro partes, sus similitudes con la película solo podrán ser juzgadas por quien conozca la trama de esta última; ${ }^{1}$ esto es, la prueba definitiva de que Perojo no prescindió, ni mucho menos, del esquema que había más que abocetado Periquet padre.

1 En el guión, las protagonistas son la tonadillera Petrilla y la condesa de Gualda. Las dos han tenido amores con Fernando, marqués de Nuévalos, aunque la primera también se deja querer por el corregidor Ondarza. Al igual que en la película, el primer cuadro consiste en el altercado en que este último, siguiendo a la celosa Petrilla mientras ella espía a su amante en el palacio de la aristócrata, resulta muerto en un duelo con el marquesito. El segundo acto consiste en la venganza de Petrilla, aprovechando que coincide con un político en una venta -aunque en el guión original éste no es un ministro cualquiera, sino nada menos que Godoy: la joven se deja seducir a cambio de que el Príncipe de la Paz firme una carta mandando al marquesito a las Indias. En el tercero, la condesa, que intenta a la desesperada evitar que su amado sea condenado al ostracismo, es confundida por Paquiro, a quien Petrilla despreció, con ella. Gracias a la intercesión de la reina, Fernando se salva de un destino tan indeseable. Mas (cuarta parte), mientras lo están celebrando, el noble es acuchillado por la espalda por Paquiro. 


\subsection{La virtud en el error: La calle sin sol (Rafael Gil, 1948)}

En la Historia del cine mundial, se concede un peso muy escaso, por no decir ninguno, a la cinematografía española, y brillan por su ausencia las hipotéticas aportaciones de nuestros creadores a la evolución lingüística del medio. Apenas se reconocen a nuestro cine en materia de puesta en escena y montaje al esperanto audiovisual universal los jump y shock cuts de Muerte de un ciclista (Juan Antonio Bardem, 1955), según los trabajos de Dominique Villain (1994: 118) y Barry Salt (2009: 277-278), a propósito de la mala, bufamente referenciada como Bienvenida Mr Marshall (Luis García Berlanga, 1952).

En el marco de la necesaria revisión a fondo de la aportación de la cinematografía española a la internacional, puede ser pertinente anotar una audacia técnica, narrativa, estética y discursiva presente en La calle sin sol, coherente con gestos previos de Rafael Gil, discretos pero inequívocamente intencionados, ${ }^{2}$ pero debida en este caso a la labor editorial de José Antonio Rojo en este su primer emparejamiento con el director valenciano; algo que solo Fernando Alonso Barahona ha elogiado, sin explicar por qué, al referirse al "montaje inteligente [...] en la descripción del aprendizaje del idioma por parte de Mauricio)" (1997: 59).

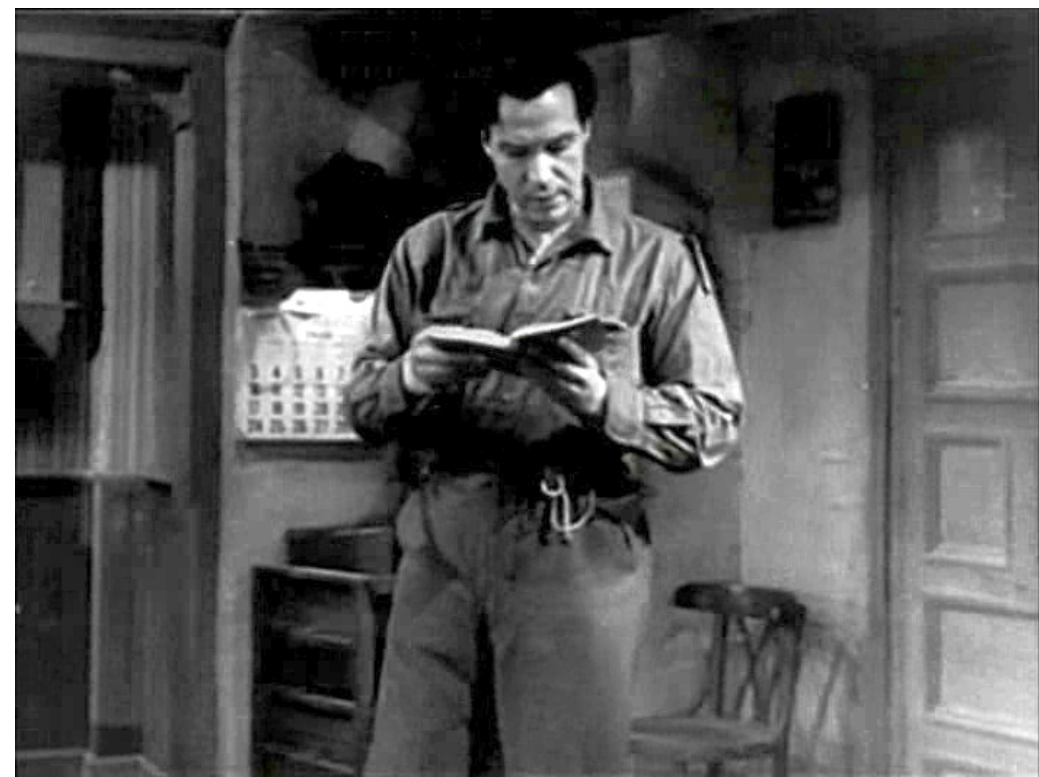

2 José Luis Castro de Paz destacó la inscripción del fantástico en la escritura de Huella de luz (1943), editada por Juan Pallejá, "por ejemplo, las puntuaciones y raccords plásticos, no narrativos, en el dinámico episodio de la verbena" y "El sutil recurso de la dirección del movimiento de la cámara (privilegiando derecha e izquierda según predomine el registro cómico o el miserabilista)" (2002: 101). 


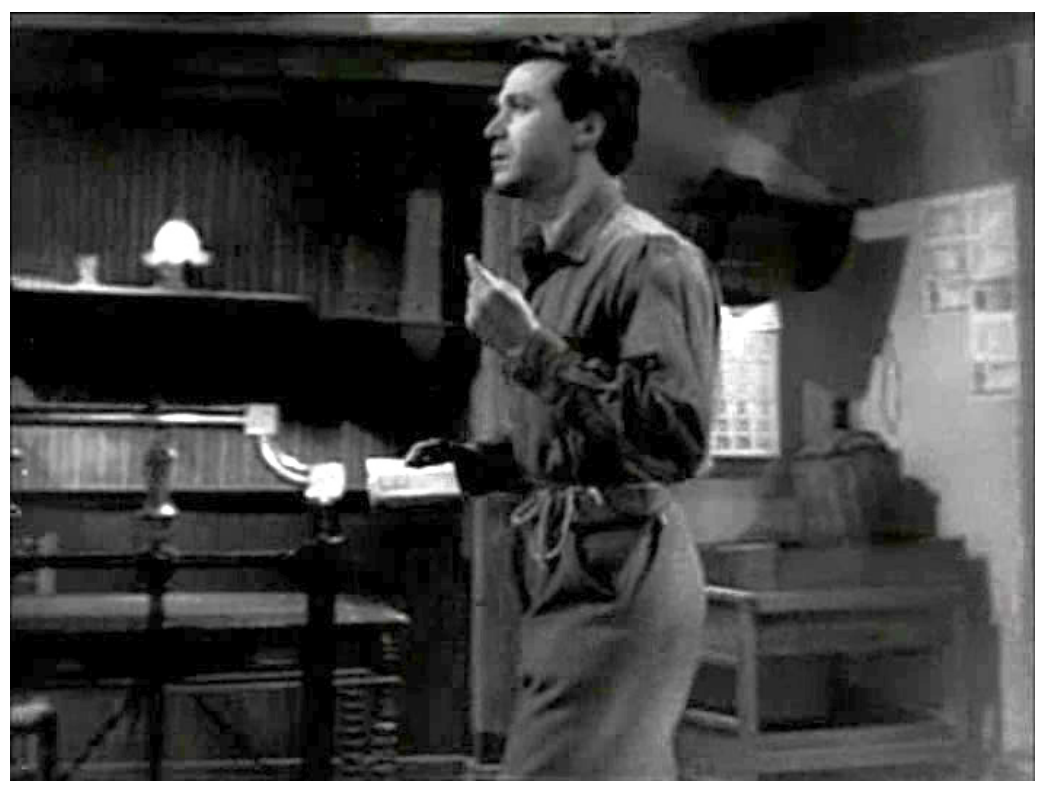

En efecto, como ilustran los fotogramas que acompañan estas líneas, consecutivos [vid. figs. 1 y 2], el tándem Gil-Rojo se marcó en el mentado montaje-secuencia un alucinante, violento jump cut, cuya función (el resumen de una acción iterativa) coincide punto por punto con la que gramaticalmente se convertiría al cabo de los años en un auténtico lugar común del esperanto modernista. No ha lugar a equívoco en cuanto a la pertinencia y deliberación de ese sintagma frecuentativo: quien suscribe comprobó su presencia en las copias en Betacam Digital y DVD disponibles en Filmoteca Española, tiradas a partir del material de preservación en $16 \mathrm{~mm},{ }^{3}$ donde se encuentran tanto la abrupta transición como la prueba definitiva, a saber: el acompañamiento musical de Manuel Parada, cuya académica partitura fluye armoniosa, escrupulosamente.

El ejemplo demuestra que La calle sin sol se adelantó tanto a las supuestas rupturas -tímidas, bajo sospecha de ser fruto de la chapucería para la miopía de analistas naïves y snobs a un tiempo- de los Bardem y Berlanga, como a las ya indiscutidamente conscientes y sistemáticas, por más que desmañadas del pope Jean-Luc Godard en Al final de la escapada (À bout de souffle, 1959).

3 Quede constancia de mi agradecimiento por su atención a Margarita Lobo y José Luis Fernández. 
2.3. Una imaginación desorbitada: Los peces rojos (José Antonio Nieves Conde, $1955)^{4}$

La contumacia del director José Antonio Nieves Conde en manifestar su disconformidad con el desenlace de Los peces rojos (1955) en entrevistas y escritos, fue el factor determinante para una infravaloración que ha durado décadas. El realizador no se conformó con denunciar su desacuerdo con el final, sino que alimentó una fantasía según la cual, primero, se opuso a que el relato se cerrara así, y propuso infructuosamente otro final; luego, que rodó o montó esa versión alternativa; por fin, que ésta llegó a distribuirse en Latinoamérica. El proceso fue gradual. En 1974, ya dio a entender a Antonio Castro que la película había circulado en dos versiones distintas:

"si hubiese logrado que se exhibiese en España, como se exhibió en otros países, con un montaje más lineal, el film hubiera resultado mucho mejor” (1974: 266).

En la entrevista que mantuvo con Antonio Gregori en 1980 -aunque publicada en 2009-, amplió el infundio hasta el escándalo:

“...el final lógico era el suicidio del personaje y en México y otros lugares pasó así [...] es, sin embargo, una de las películas españolas que más se han explotado en el mundo, ya que gracias a la explotación exterior, sobre todo en México, se estrenó en todos los cines de Hollywood" (2009: 68).

Nieves Conde añadió que había recibido - y conservaba- infinidad de telegramas, y que la película le dio allende el Atlántico "una importancia extraordinaria". No contento con ello, contó a Llinás (1995: 95) que había consultado con Censura la posibilidad de que el personaje, al final, se suicidara, lo que fue expresamente prohibido. Y en una cuarta entrevista, con Juan Cobos, dijo:

“...una vez, con Madame Ochoa [la montadora, Margarita], la montadora, hice un experimento: contar[la] de manera lineal. Y resultaba" (1997: 127).

Seguramente, lo más cerca que estuvo nunca de decir la verdad fue en la entrevista que mantuvo con José Luis Castro de Paz y Julio Pérez Perucha, en la que se limitó a decir que

“...yo quería que el protagonista se suicidase de verdad y que la chica se quedase allí, gritando... Me sucedió como a Fritz Lang, que proponía finales y no se los aceptaban" (2003: 141).

Pero el mal ya estaba hecho. La insistencia del director rindió resultado, y Francisco Llinás se hizo eco, ya en forma de descalificación, de la idea del final postizo endulzado todo un mito de la historiografía ideologizada, al afirmar que Los peces rojos

$4 \mathrm{El}$ autor del presente trabajo mantuvo con Carlos Blanco sendas entrevistas, telefónica la primera el 25 de noviembre de 2010, y personal una segunda el 12 de diciembre del mismo año en Madrid. 
“...se obliga a rematar con un convencional final feliz (LLINÁS, 1998: 625).

Por supuesto, la versión de Carlos Blanco difiere de cabo a rabo de la de Nieves Conde. A quien le ha preguntado directamente, se lo ha desmentido, y ofrecido infinidad de detalles que contradicen implícitamente a aquél. Uno de los argumentos es convincente: antes de que el director de Surcos (1951) se adhiriera al proyecto, hubo nada menos que cuatro realizadores vinculados al mismo, a saber: Joseph Leo Mankiewicz, Jack Cardiff, Henri-Georges Clouzot y Robert Siodmak. También se interesaron por él Mario Moreno, Cantinflas que quiso comprar el proyecto y protagonizarlo, y José Luis Sáenz de Heredia amigo íntimo de Blanco con quien había colaborado varias veces.

Todo ello está contado en diversas entrevistas con Blanco (COBOS, 1997 y 2001), y lo corrobora la documentación que se conserva en el Archivo General de la Administración relativa a la tramitación de un primer proyecto fallido de Los peces rojos, llevado a cabo bajo el pabellón de Castilla Films.

Según Blanco, después de cinco meses de preparativos "me falló el capitalista". Llegó a un acuerdo verbal con la Yago Films de Ángel Martínez de Olcoz, asociada a su vez a Estela Films, la empresa de Jordi Tusell, un productor procedente de Acción Católica, pero que promovería de La vida por delante (Fernando Fernán-Gómez, 1958) y luego estaría vinculado al Institut del Cinema Català (ICC)... Distribuiría la película en nuestro país Suevia Films-Cesáreo González, y en Hispanoamérica Gregorio Wallerstein.

Fue en este punto cuando se sumó a Los peces rojos José Antonio Nieves Conde, a propuesta de Martínez de Olcoz. El dueño de Yago Films era amigo personal tanto de él como de Carlos Blanco, así que organizó lo que Blanco califica de "encerrona" para forzarle a aceptar al director de Surcos. Este se encontraba en un momento profesional complicado, por las ampollas políticas que había levantado ese film -el guionista se refirió conmigo a Nieves Conde, con condescendencia retrospectiva, como "un señor que estaba en paro".

El escaso aprecio que Blanco sentía por el desempleado no se debía, claro está, a las experiencias que estaban por venir. Se habían peleado porque, habiendo sido él quien lo había propuesto como realizador para la película perdida Llegada de noche (1949) (COBOS, 1997: 121), éste, como no estaba plenamente satisfecho con el guión, había metido a sus espaldas a Gonzalo Torrente Ballester, en calidad de dialoguista de secuencias adicionales, sin comunicárselo ni mucho menos con su autorización. Blanco tenía, por tanto, motivos legítimos para sentirse afrentado, puesto que había sido él quien había puesto en marcha el proyecto de Llegada de noche, para ayudar a un guionista judío huido de la Alemania nazi a reunir el dinero suficiente para pagarse el pasaje a los Estados Unidos y mover influencias en España para que se le concediera el pasaporte.

Unos cinco años después de aquello, Blanco se avino a "perdonar" a Nieves Conde. Eso sí, acalló cualquier pretensión de autoría por su parte bajo la consigna de que "no 
podía tocar ni una coma" -"Este guión, ¿lo ves?, esto es la Biblia", sostiene que le soltó. Reconoce Blanco que Nieves Conde nunca se sintió cómodo ni con la estructura ni con el desenlace. Parece muy probable que fueran tanto las dudas que albergaba hacia los flashbacks en sí (“¿Tú estás seguro de que funcionarán, tantos? ¿No se confundirá el espectador?") como el resquemor que acumuló al tener que pasar por ese trágala, lo que alimentó un cierto rencor, creciente con el tiempo, y alentó un delirio hasta extremos casi patológicos. Lo que resulta de todo punto inverosímil es que, como el realizador aseveró, la censura prohibiera la solución del suicidio. Tal y como el propio Blanco apunta, en su Los ojos dejan huellas lo hay; y en films de los años cuarenta y cincuenta -El hombre que se quiso matar (1942), Viaje sin destino (1942), La pródiga (1946) y La calle sin sol, las cuatro de Rafael Gil; El difunto es un vivo, en las versiones de Ignacio F. Iquino (1941) y Juan Lladó (del mismo 1955)hay alusiones, tentativas y consecuciones del mismo.

Es verdad, como afirmaba José Antonio Nieves Conde, que la película se exportó a América. Quizás pesara en ello la hipotética aportación financiera del mexicano Gregorio Wallerstein, no acreditada pero a la que se han referido Esteve Riambau y Casimiro Torreiro (2008: 284). Blanco, que justo entonces se encontraba en Los Angeles intentando asentarse en la industria hollywoodiense, recuerda que la película se estrenó "en la parte vieja, el downtown" (el centro), de Los Ángeles, con subtítulos en inglés. Afirma haber asistido a una proyección. ${ }^{5}$ Según rememora, pidió al protagonista permiso para llevarse la película y hacer una proyección para la industria cinematográfica. Dice que se llevó las latas a su casa, en Olympia Boulevard -un apartamento anexo al de su socio Gary Cooper, con quien estaba intentando poner en pie el proyecto de la que casi veinte años después sería Don Quijote cabalga de nuevo (Roberto Gavaldón, 1972)-, y que con éste, con quien se encontró cuando se encaminaba a las oficinas de la Fox, las cargó en una furgoneta y siguieron el camino juntos. Allí la vieron con, entre otros, Howard Hughes y Henry Hathaway; cuando se encendieron las luces, la sala estaba llena, y todo el mundo aplaudió la película a rabiar, y le hicieron preguntas por Nieves Conde, que él respondió recomendándolo como un amigo y buen director, dotado de sensibilidad y sentido común las dos veces insistió en que siempre empleó esa fórmula para calificar al cineasta. Gary Cooper, en cambio, sólo se interesó por Emma Penella.

No hay constancia en archivos estadounidenses de la película. En cambio, se ha conseguido localizar copias fotoquímicas en México, donde contacté con la Cineteca Nacional y con la UNAM. ${ }^{6}$ Fue en esta última donde, en respuesta a mi demanda, la

5 Por más que he indagado en los anuarios de estrenos extranjeros en los Estados Unidos durante esa temporada, y en las listas de películas distribuidas de empresas especializadas en la importación de films latinos, como Clasa-Mohme, ha sido imposible confirmar este dato. Según alguna poco fiable página web, con el título traducido de Red Fish se habría estrenado en los USA el 9 de diciembre de 1955.

6 También en este caso he de agradecer su amabilidad a Francisco Ohem (UNAM) y a Ricardo Cázares Graña (Subdirector de Preservación y conservación de AcervosCineteca Nacional). 
encontraron, telecinaron ex profeso el último rollo y me la enviaron. Como sospechaba, no se distinguía ni en un solo fotograma de la versión que circuló en España, y que se conserva.

\section{Conclusiones}

El hallazgo relativo al origen de Goyescas contradice la reconstrucción de los avatares de la gestación del guión y, por extensión, la lectura que Gubern hizo del film. El ejemplo de La calle sin sol invita a dejar de anatemizar por empiristas o evenemenciales las investigaciones que pretenden señalar el valor de progreso que ciertos recursos entrañan. Mal que pese a quienes desprecian estos aspectos, la Historia se sigue escribiendo, entre otros factores, en términos de pionerismo a cargo de individuos concretos; y renunciar a esa clave solamente redunda en alimentar el concepto más vetusto y pueril de la autoría (la del director) y en prolongar el desconocimiento y el desdén que sufre nuestro cine. El análisis de la polémica en torno a Los peces rojos resulta aún más sangrante: no resulta tan lamentable que José Antonio Nieves Conde se diera a la leyenda, como que se le creyera -o no se le desmintiera-, se le permitiera esparcir la especie con total impunidad, y se impusiera una impresión crítica directamente relacionada con esa tergiversación. Lo cual, de paso, demuestra hasta qué punto el análisis, a menudo, no es tal, sino el corolario de relatos (a menudo míticos) acerca del origen de las obras; y penalizar en sí la atención a factores no textuales, un error supino.

\section{Bibliografía}

ALONSO BARAHONA, F. (1997): "Rafael Gil”, en FERNÁNDEZ-MELLADO, R. (coord.): Rafael Gil. Director de Cine. Madrid: Celeste. pp. 37-117.

CASTRO, A. (1974): El cine español en el banquillo. Valencia: Fernando Torres.

CASTRO DE PAZ, J. L.; PÉREZ PERUCHA, J. (2003): "Conversación con José Antonio Nieves Conde"; en CASTRO DE PAZ, J. L.; PÉREZ PERUCHA, J. (eds.): Tragedia e ironía. El cine de Nieves Conde. Orense: Festival de Cine Independiente. pp. 137-152.

COBOS, J. (verano de 1997): "Entrevista con Nieves Conde". En Nickel Odeon, n 7 ("Madrid y el cine"). Madrid: Nickel Odeon. pp. 120-128.

COBOS, J. (2001): Conversaciones con Carlos Blanco. Un guionista para la historia. Valladolid: 46 Semana Internacional de Cine (SEMINCI).

GREGORI, A. (2009): El cine español según sus directores. Madrid: Cátedra.

GUBERN, R. (1994): Benito Perojo. Pionerismo y supervivencia. Madrid: Filmoteca Española.

LLINÁS, F. (1995): José Antonio Nieves Conde. El oficio de cineasta. Valladolid: 40 Semana Internacional de Cine (SEMINCI). 
LLINÁS, F. (1998): “José Antonio Nieves Conde”, en BORAU, J. L. (ed): Diccionario del cine español (1896-1996). Madrid: Alianza.

RIAMBAU, E.; TORREIRO, C.: Productores en el cine español. Estado, dependencias y mercado. Madrid: Cátedra-Filmoteca Española, 2008.

SALT, B. (2009): Film Style \& Technology. History \& Analysis. London: Starword ( $3^{\text {a }}$ edición).

VILLAIN, D. (1994): El montaje cinematográfico. Madrid: Cátedra.

VV.AA.: Los peces rojos (expediente en el Archivo General de la Administración): Signaga Cajas 36/04748, 36/03519 - Carpeta 13498.

\section{El autor}

Agustín Rubio Alcover es profesor colaborador de Comunicación Audiovisual y Publicidad en el Departamento de Ciencias de la Comunicación de la Universitat Jaume I de Castellón. Entre sus publicaciones destacan dos análisis monográficos acerca de Se7en (David Fincher, 1995) y de Dos en la carretera (Two for the Road, Stanley Donen, 1967) en la colección Guías para ver y analizar cine de las editoriales Nau Llibres y Octaedro, de la que es coordinador técnico. Ha publicado El don de la imagen. Un concepto del cine contemporáneo. Volumen 1: Esperantistas (2010), en Ediciones Shangrila, en cuya revista coordina una sección de reseñas bibliográficas especializadas, "Bi(T)bliografía". Con Javier Gómez Tarín lleva un cuaderno mensual dentro de El Viejo Topo de actualidad político-cinematográfica, "La mirada esquinada. Doble(s) sentido(s)". Es jefe de redacción de Archivos de la Filmoteca. Su último libro, Vicente Escrivá. Película de una España, será publicado por el Instituto Valenciano del Audiovisual y la Cinematografía Ricardo Muñoz Suay. 